\title{
BMJ Open Non-communicable diseases are the leading cause of mortality in rural Birbhum, West Bengal, India: a sex- stratified analysis of verbal autopsies from a prospective cohort, 2012-2017
}

Rajesh Kumar Rai (D) , ${ }^{1,2,3,4}$ Anamitra Barik, ${ }^{1,5}$ Saibal Mazumdar, ${ }^{1}$ Kajal Chatterjee, ${ }^{1}$ Yogeshwar V Kalkonde (D) , ${ }^{6}$ Prashant Mathur, ${ }^{7}$ Abhijit Chowdhury, ${ }^{1,8,9}$ Wafaie W Fawzi (10) 2,10,11

To cite: Rai RK, Barik A, Mazumdar S, et al. Noncommunicable diseases are the leading cause of mortality in rural Birbhum, West Bengal, India: a sexstratified analysis of verbal autopsies from a prospective cohort, 2012-2017. BMJ Open 2020;10:e036578. doi:10.1136/ bmjopen-2019-036578

- Prepublication history for this paper is available online To view these files, please visit the journal online (http://dx.doi. org/10.1136/bmjopen-2019036578).

RKR and $A B$ are joint first authors.

Received 21 December 2019 Revised 26 June 2020 Accepted 19 August 2020
Check for updates

(c) Author(s) (or their employer(s)) 2020. Re-use permitted under CC BY-NC. No commercial re-use. See rights and permissions. Published by BMJ.

For numbered affiliations see end of article.

Correspondence to

Rajesh Kumar Rai;

rajesh.iips28@gmail.com

\section{ABSTRACT}

Objectives There is a dearth of data on causes of death in rural India, which impedes identification of public health priorities to guide health interventions. This study aims to offer insights from verbal autopsies, to understand the pattern and distribution of causes of death in a rural area of Birbhum District, West Bengal, India.

Design Causes of death data were retrieved from a prospective vital event surveillance system.

Setting The Birbhum Population Project, a Health and Demographic Surveillance System, West Bengal, India. Participants Between January 2012 and December 2017, all deaths were recorded.

Main outcome measures Trained Surveyors tracked all deaths prospectively and used a previously validated verbal autopsy (VA) tool to record causes of death. Experienced physicians reviewed completed VA forms, and assigned cause of death using the 10th version of International Classification of Diseases. In addition to cause-specific mortality fraction, cause-specific crude death rate (CDR) among males and females were estimated.

Results A total of 2320 deaths (1348 males and 972 females) were recorded. An estimated CDR was $708 / 100000$. Over half of all deaths (1176 deaths, $50.7 \%$ ) were attributed to non-communicable diseases (NCDs), with nearly $30 \%$ of all deaths attributed to circulatory system disorders; whereas $24.2 \%$ and $3.9 \%$ deaths were due to cerebrovascular diseases and ischaemic heart disease, respectively. Equal percent $(13 \%)$ of males died from external causes and from infectious and parasitic diseases, and $11 \%$ died from respiratory system-related diseases. Among females, $12 \%$ died from infectious and parasitic diseases. Among children aged $0-4$ years, $50 \%$ of all male deaths and $45 \%$ of all female deaths were attributed to conditions in the perinatal period.

Conclusions NCDs are the leading cause of death among adults in a select population of rural Birbhum, India. Health programmes for rural India should prioritise plans to mitigate deaths due to NCDs.

\section{Strengths and limitations of this study}

- Given the lack of sufficient data on causes of death from rural India, cause-specific mortality data from a vital event surveillance system in rural West Bengal highlights emerging health priorities in a rural area.

- Cause of death data from 6 consecutive years (from January 2012 to December 2017) from a populationbased prospective cohort provides stable estimates of mortality in a rural setting.

- Use of a prevalidated verbal autopsy tool helped reduces possible errors and bias in determining causes of death.

- This study does not include information on multiple causes of death which might have limited contribution of other conditions to a particular death.

- As this study setting is limited to a rural area of West Bengal, careful interpretation and cautious generalisability of study findings are needed.

\section{INTRODUCTION}

India is undergoing a rapid epidemiological transition and deaths due to noncommunicable diseases (NCDs) have exceeded deaths from communicable, maternal, neonatal and nutritional diseases between 1990 and 2016. ${ }^{1}$ The variation in the extent of epidemiological transition in India demonstrated by the Global Burden of Disease (GBD) study ${ }^{1}$ suggests that tackling a specific disease burden requires robust evidence on the causes of death in order to facilitate a context-specific disease prevention strategy that varies between states. However, recording deaths and assigning cause to them has been a challenge in low-and-middle income countries where one in two deaths go unrecorded and India is no exception. ${ }^{2} 3$ A majority of India's population live in rural 
areas where access to healthcare is difficult. A significant proportion of deaths in rural areas occur outside formal medical facilities, ${ }^{4}$ and information on cause of death at a population level is rare, hampering population-specific health strategies to address local disease burden. The government health system remains an important source of healthcare in rural and underdeveloped regions of India but it focuses predominantly on infectious diseases and maternal and child health given the prevalence of these conditions in rural areas. Given socioeconomic changes and ageing populations in rural areas, chronic diseases are likely to emerge as a health priority, thus estimates on cause-specific mortality from rural India is the need of the hour.

Against this backdrop, we used verbal autopsies to examine the pattern and distribution of causes of death among males and females during 2012-2017, as part of the Birbhum Population Project (BIRPOP), a health and demographic surveillance system (HDSS) operating under the ambit of the Society for Health and Demographic Surveillance (BIRPOP-SHDS) in the Birbhum district of the state of West Bengal, India. Although primarily rural, the study population is considered at a high risk for NCDs (cardiovascular disease, cancer, diabetes and chronic respiratory disease), where both metabolic risk factors and modifiable risk factors of NCDs- tobacco use, physical inactivity, unhealthy diet and the harmful use of alcohol have been observed. ${ }^{5}$ Estimates of causes of deaths from this study complement existing literature on causes of death in rural India with a way forward to devise suitable interventions to avert preventable deaths.

\section{METHODS}

\section{Study setting and population}

The database used for this study is part of the vital events (fertility, mortality, migration and marriage) surveillance system within BIRPOP-SHDS. ${ }^{6}$ BIRPOP-SHDS is located in Birbhum district in the state of West Bengal, India, covering four administrative blocks, namely Mohammad Bazar, Rajnagar, Sainthia and Suri-I (figure 1). Established in 2008, the population cohort consists of 59395 individuals residing in 13053 households spread across 351 villages. ${ }^{6}$ These villages were selected using a simple stratified self-weighted random sampling method which used the total villages in the district as per the Indian National Census conducted in 2001 and the sampling was entrusted to a team of large-scale sample survey experts from reputed universities. By virtue of its sampling design, the cohort of population is representative of administrative blocks covered under BIRPOP-SHDS. BIRPOP-SHDS represents nearly $16 \%$ of the Birbhum district's population, which is listed as a rural and economically underdeveloped area by the State Government of West Bengal. Birbhum has also been included among the country's aspirational districts by the National Institution for Transforming India (NITI) Aayog (Aayog is synonymous with Commission), a policy think tank of the federal Indian

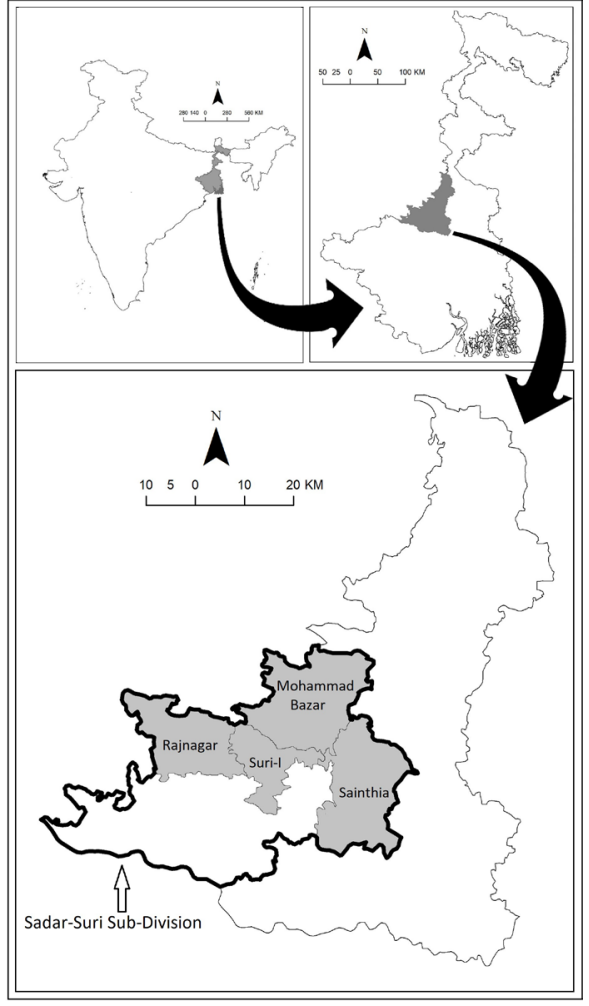

Figure 1 Study location of Birbhum Population Project, covering four administrative blocks (Mohammad Bazar, Rajnagar, Sainthia and Suri-I) of Birbhum District, West Bengal, India.

government. The socioeconomic and demographic statistics of BIRPOP-SHDS have earlier been published and are publicly available. ${ }^{6}$

BIRPOP-SHDS is solely financed by the West Bengal State Department of Health and Family Welfare, India and research findings of BIRPOP-SHDS have an important role in health policy decision making in the state. To date, BIRPOP has undertaken three rounds (2008-2009, 20122013 and 2017-2018) of cohort surveys on various health and demographic indicators. Collecting information on vital events is part of the regular survey activity, and depending on the information gathered on vital events, the database is updated continuously.

\section{Data collection on causes of death}

The information on causes of death is collected by a trained Surveyor who has at least an undergraduate degree and can speak a local language-Bengali or Santhali. BIRPOP-SHDS has 44 full-time salaried Surveyors who gather information from households on vital events. Following their recruitment, surveyors undergo stringent training for 7 working days on conducting a verbal autopsy (VA) and other vital events by experienced physicians who are also co-authors $(\mathrm{AB}, \mathrm{SM}, \mathrm{KC}$ and $\mathrm{AC})$ of this paper. After the training, the surveyors underwent two rounds of written tests followed by a mock test on VA data recording, and they had to score over $95 \%$ marks in both types of tests to be eligible for VA data collection. Training for VA data collection given to surveyors of 
BIRPOP-SHDS is comparable to community healthcare workers in India; however, surveyors of BIRPOP-SHDS are limited to data collection while community healthcare workers are expected to provide healthcare services to households. A study in Ballabgarh HDSS in northern India showed that health workers can be trained to use VA to ascertain the cause of death with precision. ${ }^{7}$ Surveyors of BIRPOP-SHDS are recruited from communities being surveyed which helps to track the death of a person in the area. Once the death of a member is confirmed, a surveyor of BIRPOP-SHDS pays a visit to the deceased member's household within a day of the death to console. Surveyors attempt to locate a family member/ neighbour(s)/caretaker who could be the best possible respondents for VA within a week. If the deceased is a child aged $0-15$ years, $4-8$ weeks are allowed to pass to give time for bereavement. This method helped reduce recall errors of respondents, and helped increase the rapport with community members. In addition, nearly $10 \%$ of all deaths were resurveyed independently by assigned physicians to confirm the accuracy of information collected by the surveyors.

\section{Verbal autopsy (VA) and identification of causes of death}

VA is a tool that can be used to collect and analyse data on causes of death. VA is defined by the WHO as 'a method used to ascertain the cause of a death based on an interview with next of kin or final caregivers' that can be applied for deaths without certification of medical causes. This VA tool is widely used in developing countries and validated for its accuracy in recording, and diagnosing cause-specific mortality. ${ }^{89}$ To record the causes of death, a previously validated semistructured VA tool $^{8}$ with some structured questions and open narrative section were used. The VA method used in BIRPOP-SHDS consists of two distinct stages. First, information was collected via structured interviews with family members and caregivers of the deceased on signs, symptoms, medical history and circumstances around the time of death. Second, the information is reviewed by a panel of physicians to assign a cause of death. For this study, deaths between January 2012 and December 2017 (6 consecutive years) were analysed.

Separate VA questionnaires were developed and pilottested, one for each of three age groups: death in 0-28 days; death between 29 days and 14 years and death at age $\geq 15$ years. ${ }^{8}$ The questionnaires included questions on previously diagnosed medical conditions and a checklist of signs and symptoms occurring chronologically around the time of death. A narrative of the events leading to death was recorded as described by the respondent. When available, hospital records, medicine receipts, laboratory tests and death certificates were photocopied and included in the VA review process. Two experienced senior physicians working in a referral hospital and otherwise not involved in the surveillance study independently assessed the completed VA forms. They identified the cause of each death based on the information recorded on the form and available records. Each physician was unaware of the diagnosis assigned by the other physician. If these physicians' independent reviews of the underlying cause of death are discordant with each other, a third expert opinion from another physician is sought as an umpire reader. If all three physicians could not determine or agree on the cause of death, the death was recorded as having an unspecified cause. Of total deaths, 24 deaths were found to be discordant between two physicians, which required decision by an umpire physician through consensus opinion, hence there is no non-specified cause of death.

Guided by the algorithm of the Office of the Registrar General of India's Sample Registration System (SRS), Government of India, deaths are coded by the physicians according to the International Classification of Disease, version 10 (ICD-10). ${ }^{10}$ ICD-10 is a globally accepted manual of codes for diseases, signs and symptoms, abnormal findings, disorder, social circumstances and external causes of injury or diseases. For ICD-10 coding, physicians used underlying cause of death. For this study, all physicians that participated in reviewing causes of death had a combined experience of over 25 years in reviewing causes of death, and are co-authors (AB, SM and $\mathrm{KC}$ ) on this paper. Before data entry, data quality is checked and verified by the designated Field Monitor, followed by rechecking done by the Survey Manager.

\section{Analytical approach}

Year-wise causes of death were tabulated, and in addition to cause-specific mortality fraction, crude death rate (CDR) among males and females were calculated. CDR per year was calculated using the following formula:

\section{Total number of deaths in six years, 2012-2017 $\times 100,000$}

While calculating the rates, the exposed population was determined using the database, which was continuously updated and adjusted for any vital events, such as birth, death, marriage and migration. Descriptive statistics were calculated to note the proportion of deaths attributed by cause and stratified by age group. Combining all deaths for 2012-2017 helped to minimise the year-wise variation in the number of deaths. Analysis was conducted using statistical software Stata V.14. ${ }^{11}$

\section{Patient and public involvement}

This study used data from the vital event surveillance system of the BIRPOP-SHDS, an HDSS which recruited 59395 members of 13053 households in 2008. This cohort of participants is followed to understand the pattern of vital events. The socio-economic and demographic characteristics and public health profile of BIRPOP-SHDS are publicly available. ${ }^{6}$ At its inception in 2008, participants were informed about the study design, purpose and how it would benefit the society at large. The study protocol does not include dissemination of the results to the individual study participant. Published findings are shared with the West Bengal State Department of Health and 
Family Welfare, for their use in programme and policy making.

\section{RESULTS}

A total of 2320 deaths (1348 males and 972 females) were recorded during the period 2012-2017 (table 1). An overall CDR of 708/100 000 (95\% CI: 680-738) was estimated. The lowest number of deaths $(n=371$, CDR: 785/100 000, CI: 712-864) was recorded in 2012 and the highest number of 414 deaths (CDR: 680/100 000, CI: 612-752) in 2017. Over half of all deaths (1176 deaths, 50.7\%; CDR 359/100000, CI: 339-380) were attributed to NCDs, with $30 \%$ of all deaths attributed to circulatory system disorders; whereas $24.2 \%$ and $3.9 \%$ deaths were due to cerebrovascular diseases and ischaemic heart disease, respectively.

Among males (table 2) and females (table 3), the leading cause of death was circulatory system disorders accounting for $27 \%$ (CI: 24-29) and 34\% (CI: 31-37) deaths, respectively. Of deaths associated with the circulatory system, deaths from cerebrovascular diseases were $22 \%$ among males and 28\% among females of total deaths in the respective category. Among diseases of the circulatory system, ischaemic heart disease was the second leading cause of death with $4 \%$ of death among males and females. The second-highest number of deaths among males was attributed to external causes of mortality: 13\% (CI: 11-15) and death from infectious and parasitic diseases 13\% (CI: 12-15), whereas among females, it was infectious and parasitic diseases 12\% (CI: 10-14). The third leading cause of death among males was death related to the respiratory system-11\% (CI: 10-13), whereas among females external causes of mortality and deaths from the respiratory system disorders accounted for $9 \%$ of deaths each. Almost equal percentages of deaths were from endocrine, nutritional and metabolic diseases among males (7\%) and females (8\%). Similarly, $7 \%$ and $8 \%$ of deaths due to neoplasms were recorded among males and females, respectively.

Distribution of deaths by age group (in years: 0-4, 5-14, 15-59 and $\geq 60$ ) are presented for males (table 2) and females (table 3 ). The explanation for age-grouping is available elsewhere. ${ }^{8}$ Most deaths among children aged $0-4$ years were due to conditions in the perinatal period (male $50 \%$ and female $45 \%$ ), whereas $21 \%$ and $31 \%$ of all deaths are attributed to deaths due to infectious and parasitic diseases among male and female children, respectively. Deaths attributable to intestinal infectious diseases among female children $(29 \%)$ were relatively higher than males (17\%). For the age group 5-14 years, nearly $50 \%$ of male deaths and $45 \%$ of female deaths were due to external causes, with accidental drowning being the top cause for both groups. Deaths due to infectious and parasitic diseases appeared prevalent among males and females in the same age group. Nearly $26 \%$ of female deaths in the age group 15-59 were attributed to the circulatory system as were $20 \%$ of male deaths, with cerebrovascular disease being the prime subcause. In the same age group, the highest proportion of deaths among males was from external causes (25\%). Among females, external causes accounted for $17 \%$ of deaths. However, death due to self-harm among females was higher $(11 \%)$ than males counterparts (9\%). Among people aged $\geq 60$ years, $36 \%$ of male deaths and $44 \%$ of female deaths were due to causes associated with the circulatory system and respiratory system deaths accounted for $18 \%$ of male deaths and $12 \%$ of female deaths; within this age group. Deaths due to infectious and parasitic diseases were prevalent among both males (13\%) and females (12\%) aged $\geq 60$ years.

A sex-stratified CDR by disease group is presented in table 4. CDR among males was estimated to be higher (811, CI: 768-855) than females (603, CI: 566-642). Irrespective of sex, CDR was the highest for death related to the circulatory system, followed by death due to infectious and parasitic diseases and death due to external causes.

\section{DISCUSSION}

Using VA data collected between January 2012 and December 2017 from a Health and Demographic Surveillance System (HDSS) located in rural areas of Birbhum district of the state of West Bengal, India, we aimed to examine cause-specific mortality rate in addition to cause-specific mortality fraction. Overall, between 2012 and 2017, the crude death rate (CDR) was estimated to be higher (7.1/1000 with CI: $6.8-7.4$ or $708 / 100000$, CI: 680-738) among the studied population, as compared with the CDR of the state of West Bengal in 20165.8/1000 (CI: 5.7-6.1). ${ }^{12}$ The higher CDR in Birbhum is likely due to lower socioeconomic status and lack of healthcare access to the population. This study calls for improvement in the state's plan for overall mortality reduction in underserved areas. such as Birbhum, where this HDSS is located. The West Bengal State Department of Health and Family Welfare does not have any active roadmap or plan of action to reduce the overall mortality in the state, but the department complies with the 2017 National Health policy ${ }^{13}$ which focuses on the reduction in specific causes of death nationally.

Of all deaths, over $50 \%$ deaths were attributed to NCDs. Apart from BIRPOP-SHDS, the authors are aware of over 10 functional HDSSs in India and many more are underway. Unfortunately, published data on causes of death are only available from three HDSS': Gadchiroli and Vadu in the state of Maharashtra and Ballabgarh in Haryana. Although detailed data from these HDSSs on causes of death for the time period of our study are not available publicly for comparison, a 2014 study reported 760 deaths in Vadu HDSS and 2553 deaths in Ballabgah HDSS during 2006-2012, with the burden of NCDs higher in Ballabgarh than Vadu. ${ }^{14}$ A recent study from Gadchiroli HDSS also reported arising burden of NCDs in rural areas of India. ${ }^{15}$ The SRS developed by the Office of the Registrar General and Census Commissioner, 
Table 1 Year-wise number of deaths by cause, 2012-2017

Causes of death (ICD 10 code)

\begin{tabular}{|c|c|c|c|c|c|c|c|}
\hline \multirow[t]{2}{*}{ Causes of death (ICD 10 code) } & \multirow[b]{2}{*}{ Total deaths } & \multicolumn{6}{|l|}{ Year } \\
\hline & & 2012 & 2013 & 2014 & 2015 & 2016 & 2017 \\
\hline Blood/blood forming organs (D50-D89) & 5 & 2 & 0 & 1 & 1 & 1 & 0 \\
\hline Circulatory system (100-199) & 693 & 119 & 129 & 87 & 119 & 123 & 116 \\
\hline Cerebrovascular disease & 561 & 88 & 105 & 67 & 97 & 107 & 97 \\
\hline Ischaemic heart disease & 91 & 23 & 19 & 14 & 15 & 10 & 10 \\
\hline Other & 41 & 8 & 5 & 6 & 7 & 6 & 9 \\
\hline Conditions in the perinatal period ( $\mathrm{POO}$ & 87 & 23 & 15 & 14 & 13 & 12 & 10 \\
\hline
\end{tabular}

P96)

\begin{tabular}{|c|c|c|c|c|c|c|c|}
\hline Congenital malformations (Q00-Q99) & 7 & 0 & 2 & 1 & 1 & 2 & 1 \\
\hline Digestive system (K00-K93) & 136 & 21 & 18 & 23 & 25 & 20 & 29 \\
\hline Diseases of liver & 103 & 19 & 18 & 21 & 15 & 13 & 17 \\
\hline Other & 33 & 2 & 0 & 2 & 10 & 7 & 12 \\
\hline $\begin{array}{l}\text { Endocrine, nutritional and metabolic } \\
\text { diseases (E00-E90) }\end{array}$ & 173 & 23 & 25 & 32 & 33 & 26 & 34 \\
\hline Diabetes mellitus & 126 & 13 & 15 & 23 & 29 & 22 & 24 \\
\hline Other & 47 & 10 & 10 & 9 & 4 & 4 & 10 \\
\hline External causes of mortality (S00-Y98) & 266 & 32 & 51 & 30 & 55 & 47 & 51 \\
\hline $\begin{array}{l}\text { Contact with venomous animals and } \\
\text { plants }\end{array}$ & 8 & 0 & 1 & 1 & 2 & 3 & 1 \\
\hline Exposure to smoke, fire and flame & 32 & 2 & 11 & 1 & 6 & 5 & 7 \\
\hline Accidental drowning & 24 & 2 & 4 & 3 & 5 & 5 & 5 \\
\hline Falls & 16 & 1 & 3 & 3 & 3 & 5 & 1 \\
\hline Intentional self harm & 94 & 11 & 20 & 10 & 25 & 12 & 16 \\
\hline Transport injuries & 50 & 8 & 4 & 10 & 8 & 10 & 10 \\
\hline Other & 42 & 8 & 8 & 2 & 6 & 7 & 11 \\
\hline Genitourinary system (N00-N99) & 95 & 18 & 9 & 10 & 16 & 20 & 22 \\
\hline Infectious and parasitic diseases (A00-B99) & 294 & 57 & 41 & 54 & 37 & 46 & 59 \\
\hline Diarrhoea & 67 & 22 & 14 & 9 & 7 & 5 & 10 \\
\hline Intestinal infectious diseases & 102 & 15 & 8 & 18 & 15 & 24 & 22 \\
\hline Tuberculosis & 96 & 19 & 16 & 23 & 10 & 9 & 19 \\
\hline HIV & 2 & 0 & 0 & 0 & 0 & 1 & 1 \\
\hline Other & 27 & 1 & 3 & 4 & 5 & 7 & 7 \\
\hline Mental and behavioural disorder (F00-F99) & 1 & 0 & 1 & 0 & 0 & 0 & 0 \\
\hline Neoplasm (C00-D48) & 178 & 31 & 31 & 26 & 39 & 29 & 22 \\
\hline Lip, oral cavity and oropharynx & 34 & 5 & 6 & 4 & 8 & 7 & 4 \\
\hline Digestive organs & 61 & 9 & 11 & 13 & 15 & 5 & 8 \\
\hline Respiratory and intrathoracic organs & 10 & 3 & 3 & 0 & 2 & 2 & 0 \\
\hline Male/female genital organs & 12 & 1 & 1 & 1 & 2 & 4 & 3 \\
\hline III-defined and unspecific sites & 1 & 0 & 0 & 0 & 0 & 0 & 1 \\
\hline Other & 60 & 13 & 10 & 8 & 12 & 11 & 6 \\
\hline Nervous system (G00-G99) & 43 & 6 & 9 & 4 & 5 & 8 & 11 \\
\hline Not elsewhere classifiable (R00-R99) & 84 & 5 & 12 & 14 & 22 & 25 & 6 \\
\hline III-defined cause of death & 4 & 1 & 1 & 0 & 1 & 1 & 0 \\
\hline Incomplete history & 50 & 3 & 8 & 6 & 13 & 17 & 3 \\
\hline Sudden & 24 & 1 & 3 & 7 & 7 & 5 & 1 \\
\hline Others & 6 & 0 & 0 & 1 & 1 & 2 & 2 \\
\hline
\end{tabular}




\begin{tabular}{|c|c|c|c|c|c|c|c|}
\hline \multirow[t]{2}{*}{ Causes of death (ICD 10 code) } & \multirow[b]{2}{*}{ Total deaths } & \multicolumn{6}{|l|}{ Year } \\
\hline & & 2012 & 2013 & 2014 & 2015 & 2016 & 2017 \\
\hline $\begin{array}{l}\text { Pregnancy, childbirth and the puerperium } \\
\text { (O00-099) }\end{array}$ & 3 & 1 & 1 & 0 & 0 & 0 & 1 \\
\hline Respiratory system (J00-J99) & 245 & 33 & 42 & 45 & 43 & 33 & 49 \\
\hline Respiratory and intrathoracic organs & 4 & 1 & 1 & 0 & 0 & 1 & 1 \\
\hline COPD/asthma & 239 & 33 & 42 & 45 & 43 & 32 & 44 \\
\hline Other & 2 & 0 & 0 & 0 & 0 & 1 & 1 \\
\hline Skin and subcutaneous tissue (L00-L99) & 8 & 0 & 0 & 2 & 1 & 2 & 3 \\
\hline $\begin{array}{l}\text { Diseases of the musculoskeletal system } \\
\text { (M00-M99) }\end{array}$ & 2 & 0 & 0 & 0 & 0 & 2 & 0 \\
\hline Total & 2320 & 371 & 386 & 343 & 410 & 396 & 414 \\
\hline
\end{tabular}

Bold values represent statistics for overall disease group, as per ICD 10.

COPD, chronic obstructive pulmonary disease; ICD 10, International Classification of Disease, version 10.

Ministry of Home Affairs, Government of India ${ }^{16}$ provides information on state-wide causes of death for India. Besides, global research group such as the GBD Study ${ }^{1}$ also provides model based estimates on causes of death in India at the national and subnational level. However, state level estimates often do not provide information on rural areas separately and may not be suitable to devise community-based interventions in rural settings. A handful of regional studies ${ }^{814} 15$ in India have also made an effort to study causes of death. State level estimates are often not suitable indicators to devise community-based interventions and to bridge this gap, the work of HDSS' such as BIRPOP-SHDS, offer valuable insights for public health policy making to deliver effective and sustainable interventions, especially for rural India where most Indians reside.

Nearly $30 \%$ of overall deaths are attributed to the circulatory system in this studied population and cerebrovascular disease was the leading cause of death. This finding is in contrast with a study conducted in rural Andhra Pradesh $^{8}$ and the GBD study for West Bengal ${ }^{1}$ where ischaemic heart disease was the leading cause of death and disability. Our findings concur with a study in Gadchiroli HDSS where cerebrovascular disease was the leading cause of death and accounted for $14 \%$ of all deaths. ${ }^{415} \mathrm{In}$ India, deaths due to ischaemic heart disease exceed those due to cerebrovascular diseases. However, in our study the reverse was seen. A recent nationally representative study ${ }^{17}$ has found higher mortality due to cerebrovascular diseases in north-eastern states of India where West Bengal is located. The reasons for a higher risk of stroke will need further investigations. The deaths from cerebrovascular diseases in the BIRPOP-SHDS study area was higher among females than males which could be due to higher prevalence of overweight and obesity, ${ }^{18}$ metabolic syndrome, ${ }^{19}$ type 2 diabetes mellitus, ${ }^{20}$ hypertension ${ }^{21}$ and other cardiometabolic risk factors ${ }^{22}$ among females. A population-based study from the city of Kolkata in the state of West Bengal had also reported higher incidence and case fatality due to stroke among females. ${ }^{23}$

External causes of mortality among both males and females appeared to be dominant in the age group 5-59 years. While drowning accounted for $1 \%$ of all deaths in the age group of 5-14 years, $20 \%$ of all deaths were due to accidental drowning which demands urgent attention and intervention. Drowning in West Bengal ranks 14th in causes of years of life lost in 2016. ${ }^{1}$ A cross-sectional study in Andhra Pradesh also registered 1\% of total deaths due to drowning during 2003-2004. ${ }^{8}$ Potential reasons for higher accidental drowning among 5-14 years age group could be extensive use of home side ponds in this area for rearing fishes and limited supervision. ${ }^{24}$

Death due to intentional self-harm appeared to be another puzzle among adult deaths in rural India, and this finding concurs with the study conducted in rural Andhra Pradesh, ${ }^{8}$ and the GBD study estimated that self-harm is the fourth leading cause $(3.7 \%)$ of disabilityadjusted life years (DALYs) in West Bengal in 2016. ${ }^{1}$ Studies conducted in rural Haryana, ${ }^{25}$ and Gadchiroli ${ }^{15}$ also showed a high level of intentional self-harm such as death by suicide-3.5\% and $2.5 \%$, respectively. A study from BIRPOP-SHDS showed that this region has a high burden of probable psychiatric disorder $(26 \%)$, which might be a contributing factor. ${ }^{26}$ Deaths due to infectious and parasitic diseases among all age groups for both males and females was high with the highest percentage of deaths in the age group of $0-4$ years. This is in contrast to a study conducted in rural Andhra Pradesh, ${ }^{8}$ where deaths due to intestinal infectious diseases were recorded higher among age group 5-14.

Our finding that the third leading cause of overall death is the respiratory system associated with chronic obstructive pulmonary disease (COPD)/asthma. The GBD study also reported COPD as the third leading cause of DALYs in West Bengal. ${ }^{1}$ An earlier study from BIRPOP-SHDS showed around half of the adult male population smoke, 
Table 2 Causes of death among males, by age group

\begin{tabular}{|c|c|c|c|c|c|c|}
\hline \multirow[b]{2}{*}{ Causes of death (ICD 10 code) } & \multirow[b]{2}{*}{$\begin{array}{l}\text { Total } \mathrm{N} \text { of } \\
\text { deaths }\end{array}$} & \multirow{2}{*}{$\begin{array}{l}\text { Cause-specific } \\
\text { mortality fraction } \\
(95 \% \mathrm{Cl})^{\star} \dagger\end{array}$} & \multicolumn{4}{|c|}{ Mortality fraction by age group* } \\
\hline & & & $\begin{array}{l}0-4 \\
(n=101)\end{array}$ & $\begin{array}{l}5-14 \\
(n=20)\end{array}$ & $\begin{array}{l}15-59 \\
(n=523) \\
\end{array}$ & $\geq 60(n=704)$ \\
\hline $\begin{array}{l}\text { Blood/blood forming organs (D50- } \\
\text { D89) }\end{array}$ & 5 & 0.4 & 4 & 5 & 0.0 & 0.0 \\
\hline Circulatory system (100-199) & 361 & 27 (24-29) & 6 & 0.0 & 20 & 36 \\
\hline Cerebrovascular disease & 291 & 22 & 1 & 0.0 & 16 & 29 \\
\hline Ischaemic heart disease & 54 & 4 & 0.0 & 0.0 & 2 & 6 \\
\hline Other & 16 & 1 & 5 & 0.0 & 2 & 0.4 \\
\hline $\begin{array}{l}\text { Conditions in the perinatal period } \\
\text { (P00-P96) }\end{array}$ & 50 & $4(3-5)$ & 50 & 0.0 & 0.0 & 0.0 \\
\hline Congenital malformations (Q00-Q99) & 4 & 0.3 & 4 & 0.0 & 0.0 & 0.0 \\
\hline Digestive system (K00-K93) & 92 & $7(6-8)$ & 0.0 & 10 & 10 & 5 \\
\hline Diseases of liver & 64 & 5 & 0.0 & 10 & 7 & 4 \\
\hline Other & 28 & 2 & 0.0 & 0.0 & 3 & 2 \\
\hline $\begin{array}{l}\text { Endocrine, nutritional and metabolic } \\
\text { diseases (E00-E90) }\end{array}$ & 94 & $7(6-8)$ & 2 & 0.0 & 7 & 8 \\
\hline Diabetes mellitus & 81 & 6 & 2 & 0.0 & 7 & 6 \\
\hline Other & 13 & 1 & 0.0 & 0.0 & 1 & 1 \\
\hline $\begin{array}{l}\text { External causes of mortality (S00- } \\
\text { Y98) }\end{array}$ & 177 & $13(11-15)$ & 6 & 50 & 25 & 4 \\
\hline $\begin{array}{l}\text { Contact with venomous animals } \\
\text { and plants }\end{array}$ & 2 & 0.1 & 0.0 & 0.0 & 0.2 & 0.1 \\
\hline Exposure to smoke, fire and flame & 19 & 1 & 1 & 10 & 3 & 0.3 \\
\hline Accidental drowning & 18 & 1 & 3 & 20 & 2 & 0.4 \\
\hline Falls & 13 & 1 & 0.0 & 5 & 2 & 0.3 \\
\hline Intentional self harm & 54 & 4 & 0.0 & 5 & 9 & 1 \\
\hline Transport injuries & 42 & 3 & 0.0 & 10 & 7 & 0.6 \\
\hline Other & 29 & 2 & 2 & 0.0 & 3 & 2 \\
\hline Genitourinary system (NO0-N99) & 59 & $4(3-6)$ & 0.0 & 5 & 6 & 4 \\
\hline $\begin{array}{l}\text { Infectious and parasitic diseases } \\
\text { (A00-B99) }\end{array}$ & 181 & $13(12-15)$ & 21 & 10 & 13 & 13 \\
\hline Diarrhoea & 33 & 2 & 2 & 0.0 & 2 & 3 \\
\hline Intestinal infectious diseases & 52 & 4 & 17 & 5 & 1 & 4 \\
\hline Tuberculosis & 76 & 6 & 1 & 5 & 7 & 5 \\
\hline HIV & 2 & 0.1 & 0.0 & 0.0 & 0.4 & 0.0 \\
\hline Other & 18 & 1 & 1 & 0.0 & 2 & 0.7 \\
\hline $\begin{array}{l}\text { Mental and behavioural disorder } \\
\text { (F00-F99) }\end{array}$ & 1 & 0.1 & 0.0 & 0.0 & 0.2 & 0.0 \\
\hline Neoplasm (C00-D99) & 99 & $7(6-9)$ & 0.0 & 5 & 9 & 8 \\
\hline Lip, oral cavity and oropharynx & 29 & 2 & 0.0 & 0.0 & 2 & 2 \\
\hline Digestive organs & 30 & 2 & 0.0 & 0.0 & 2 & 3 \\
\hline $\begin{array}{l}\text { Respiratory and intrathoracic } \\
\text { organs }\end{array}$ & 8 & 0.6 & 0.0 & 0.0 & 0.4 & 0.9 \\
\hline Male genital organs & 1 & 0.1 & 0.0 & 0.0 & 0.2 & 0.0 \\
\hline III-defined and unspecific sites & 1 & 0.1 & 0.0 & 0.0 & 0.0 & 0.1 \\
\hline Other & 30 & 2 & 0.0 & 5 & 3 & 2 \\
\hline Nervous system (G00-G99) & 25 & 2 & 4 & 10 & 3 & 0.6 \\
\hline
\end{tabular}


Table 2 Continued

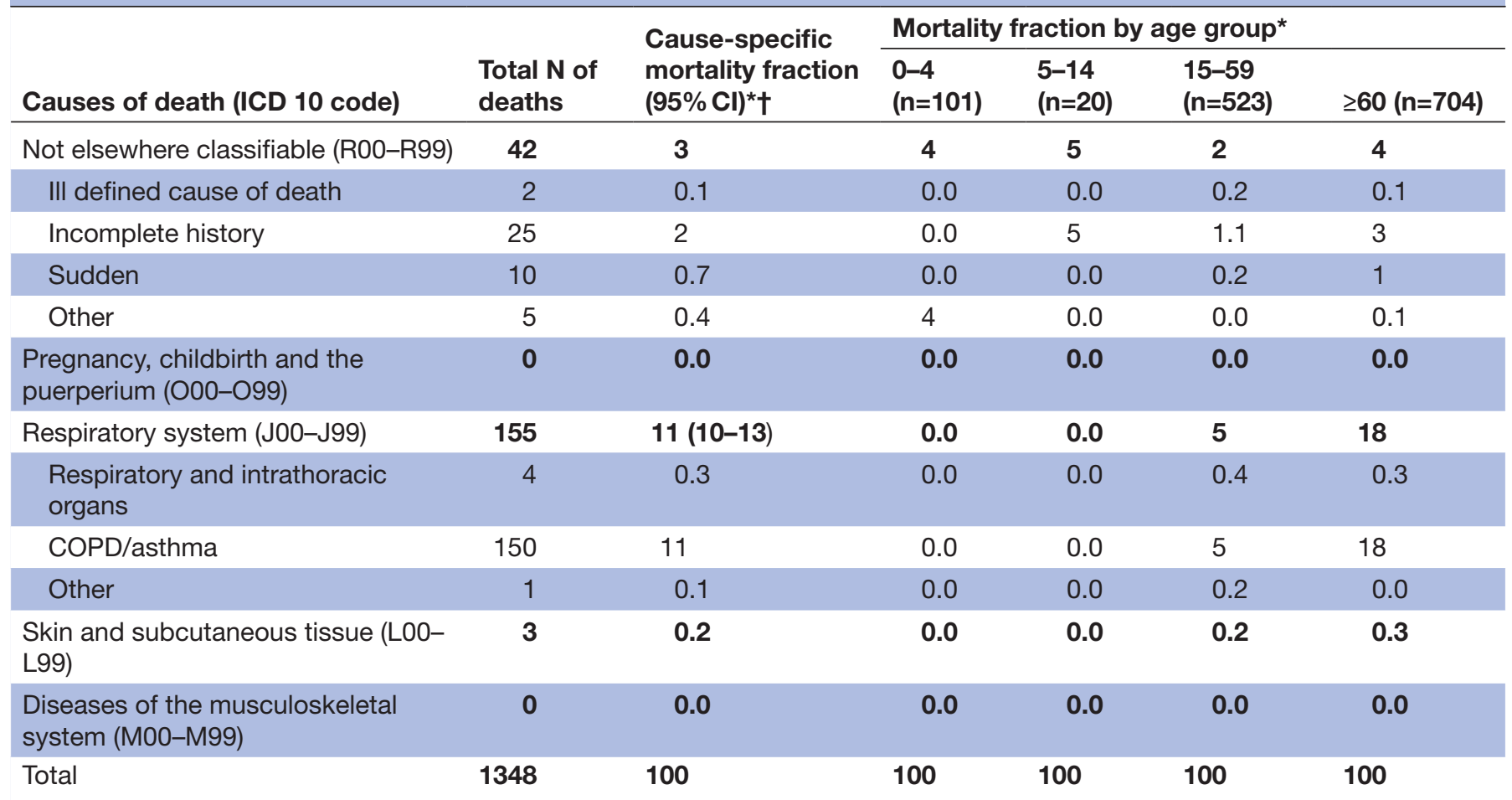

Bold values represent statistics for overall disease group, as per ICD 10.

*Values above one rounded to nearest whole number and values less than one reported to one decimal place. Totals may not add precisely due to rounding.

†95\% Cls have been provided where 50 or more deaths were reported.

COPD, chronic obstructive pulmonary disease; ICD 10, International Classification of Disease, version 10.

which is a risk factor for COPD.$^{27}$ Higher proportion of deaths due to endocrine, nutritional, metabolic diseases and neoplasms in our study is consistent with the estimates of the GBD study in West Bengal. ${ }^{1}$ In-depth investigation by public health researchers and programme and policy makers is needed to respond to this challenge.

In spite of its usefulness in resource poor settings to assign broader causes of death, the VA method has several limitations. However, there is no single bestperforming coding method for verbal autopsies, whether it is computer-coded verbal autopsy or physician-certified verbal autopsy (PCVA), and it is recommended to use a method that is simple and validated in various contexts, especially in rural settings. ${ }^{28}$ Overall, if undertaken with strict protocol, the PCVA method (used in this study) for ascertaining and attributing causes of death could prove comparable and with all available methods. This study followed the authenticated guideline consistent with all available methods of causes of death review advised by the Government of India. ${ }^{9}$ After sufficient brainstorming of various studies and metrics of VA, we could not arrive at any other method that would yield a different verdict on the death audits. Second, this study does not include information on multiple causes of death which might have limited understanding of the contribution of other conditions to a death. ${ }^{29}$ Although VA works well for some diseases such as measles, whooping cough which are of public health importance and bear specific symptoms, it might not be useful in cases of diseases of immense public health importance which have less specific symptoms such as HIV or malaria. Third, though we acknowledge the possibility of under-reporting of deaths attributable to tuberculosis (TB) or HIV as they are generally stigmatised, various government initiatives have already significantly curbed the prevalence of these diseases in the study area. In BIRPOP-SHDS survey area, Accredited Social Health Activists (village level health workers), with the supervision of the Senior Treatment Supervisor, undertake household visits for active TB case finding biannually. The routine sputum collection is around the stipulated target of 1200 samples per 100000 population per year, indicating the robustness of the National TB Elimination Programme. The HIV surveillance programme in the BIRPOP-SHDS area ensured 100\% HIV testing of antenatal mother's with less than $0.1 \%$ HIV prevalence. Thus the robustness of TB and HIV surveillance helped generate awareness among people covered under the BIRPOP-SHDS area. In addition, good rapport of the Surveyors with the community members helped reduce the underreporting of such occurrences. Fourth, the age-sex structure (figure 2) of the sampled population of BIRPOP-SHDS (as in 2017) was compared with the district representative data retrieved from the National Family Health Survey, 2015-2016, ${ }^{30}$ to understand the 
Table 3 Causes of death among females, by age group

\section{Causes of death (ICD 10 code)}

\section{Cause-specific deaths \\ $(95 \% \mathrm{Cl})$}

Mortality fraction by age group

$\begin{array}{llll} & 5-14 & 15-59 & \geq 60 \\ 0-4(n=83) & (n=22) & (n=301) & (n=566)\end{array}$

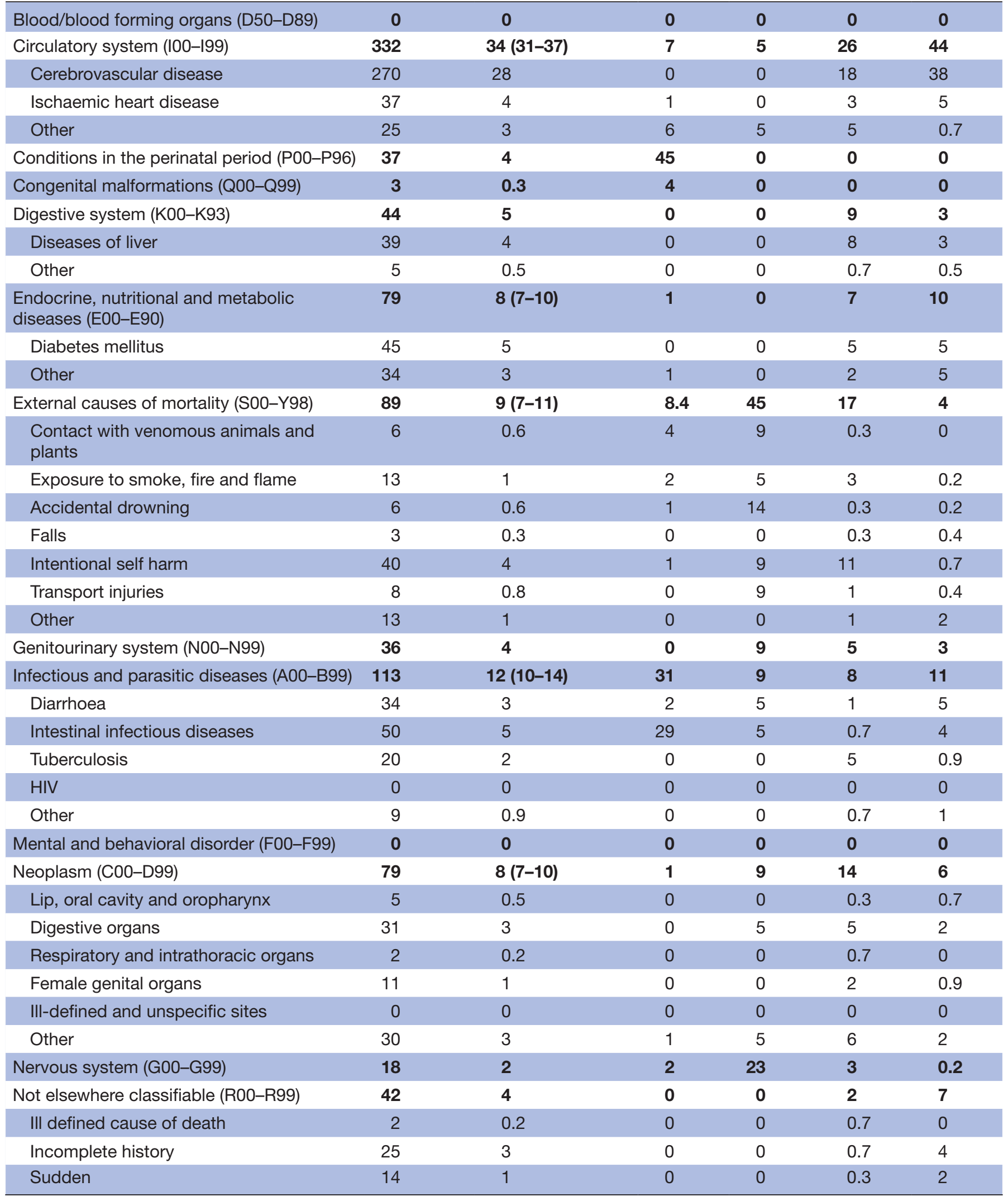

Continued 


\begin{tabular}{|c|c|c|c|c|c|c|}
\hline \multirow[t]{2}{*}{ Causes of death (ICD 10 code) } & \multirow{2}{*}{$\begin{array}{l}\text { Total } \mathrm{N} \text { of } \\
\text { deaths }\end{array}$} & \multirow{2}{*}{$\begin{array}{l}\text { Cause-specific } \\
\text { mortality fraction } \\
(95 \% \mathrm{Cl})\end{array}$} & \multicolumn{4}{|c|}{ Mortality fraction by age group } \\
\hline & & & $0-4(n=83)$ & $\begin{array}{l}5-14 \\
(n=22)\end{array}$ & $\begin{array}{l}15-59 \\
(n=301)\end{array}$ & $\begin{array}{l}\geq 60 \\
(n=566)\end{array}$ \\
\hline Other & 1 & 0.1 & 0 & 0 & 0 & 0.2 \\
\hline $\begin{array}{l}\text { Pregnancy, childbirth and the puerperium } \\
\text { (O00-099) }\end{array}$ & 3 & 0.3 & 0 & 0 & 1 & 0 \\
\hline Respiratory system (J00-J99) & 90 & $9(8-11)$ & 0 & 0 & 7 & 12 \\
\hline Respiratory and intrathoracic organs & 0 & 0 & 0 & 0 & 0 & 0 \\
\hline COPD/asthma & 89 & 9 & 0 & 0 & 7 & 12 \\
\hline Other & 1 & 0.1 & 0 & 0 & 0.3 & 0 \\
\hline Skin and subcutaneous tissue (L00-L99) & 5 & 0.5 & 0 & 0 & 0.3 & 0.7 \\
\hline $\begin{array}{l}\text { Diseases of the musculoskeletal system } \\
\text { (M00-M99) }\end{array}$ & 2 & 0.2 & 0 & 0 & 0.3 & 0.2 \\
\hline Total & 972 & 100 & 100 & 100 & 100 & 100 \\
\hline
\end{tabular}

Bold values represent statistics for overall disease group, as per ICD 10.

*Values above one rounded to nearest whole number and values less than one reported to one decimal place. Totals may not add precisely due to rounding.

+95\% Cls have been provided where 50 or more deaths were reported.

COPD, chronic obstructive pulmonary disease; ICD 10, International Classification of Disease, version 10.

Table 4 CDR by causes of death, stratified by sex

\begin{tabular}{|c|c|c|c|c|}
\hline \multirow[b]{2}{*}{ Causes of death (ICD 10 code) } & \multicolumn{2}{|c|}{$\begin{array}{l}\text { Male } \\
\text { (number of exposed population: } \\
166284 \text { ) }\end{array}$} & \multicolumn{2}{|c|}{$\begin{array}{l}\text { Female } \\
\text { (number of exposed } \\
\text { population: } 161226 \text { ) }\end{array}$} \\
\hline & $\begin{array}{l}\text { Number of } \\
\text { death }\end{array}$ & $\begin{array}{l}\text { CDR }(95 \% \mathrm{Cl}) / \\
100000\end{array}$ & $\begin{array}{l}\text { Number of } \\
\text { death }\end{array}$ & $\begin{array}{l}\text { CDR } \\
(95 \% \mathrm{CI}) / 100000\end{array}$ \\
\hline Blood/blood forming organs (D50-D89) & 5 & $3(1-7)$ & 0 & $\mathrm{nc}$ \\
\hline Circulatory system (100-199) & 361 & $217(195-241)$ & 332 & $206(184-229)$ \\
\hline Conditions in the perinatal period (P00-P96) & 50 & $30(22-40)$ & 37 & $23(16-32)$ \\
\hline Congenital malformations (Q00-Q99) & 4 & $2(1-6)$ & 3 & $2(0-5)$ \\
\hline Digestive system (K00-K93) & 92 & $55(45-68)$ & 44 & $27(20-37)$ \\
\hline Endocrine, nutritional and metabolic diseases (E00-E90) & 94 & $57(46-69)$ & 79 & $49(39-61)$ \\
\hline External causes of mortality (S00-Y98) & 177 & $106(91-123)$ & 89 & $55(44-68)$ \\
\hline Genitourinary system (N00-N99) & 59 & $35(27-46)$ & 36 & $22(16-31)$ \\
\hline Infectious and parasitic diseases (A00-B99) & 181 & $109(94-126)$ & 113 & $70(58-84)$ \\
\hline Mental and behavioural disorder (F00-F99) & 1 & $1(0-3)$ & 0 & $\mathrm{nc}$ \\
\hline Neoplasm (C00-D99) & 99 & $60(48-72)$ & 79 & $49(39-61)$ \\
\hline Nervous system (G00-G99) & 25 & $15(10-22)$ & 18 & $11(7-18)$ \\
\hline Not elsewhere classifiable (R00-R99) & 42 & $25(18-34)$ & 42 & $26(19-35)$ \\
\hline Pregnancy, childbirth and the puerperium (O00-O99) & 0 & $\mathrm{nc}$ & 3 & $2(0-5)$ \\
\hline Respiratory system (J00-J99) & 155 & $93(79-109)$ & 90 & $56(45-69)$ \\
\hline Skin and subcutaneous tissue (L00-L99) & 3 & $2(0-5)$ & 5 & $3(1-7)$ \\
\hline Diseases of the musculoskeletal system (M00-M99) & 0 & $\mathrm{nc}$ & 2 & $1(0-4)$ \\
\hline Total & 1348 & $811(768-855)$ & 972 & 603 (566-642) \\
\hline
\end{tabular}

CDR, crude death rate; ICD 10, International Classification of Disease, version 10; nc, not calculated. 


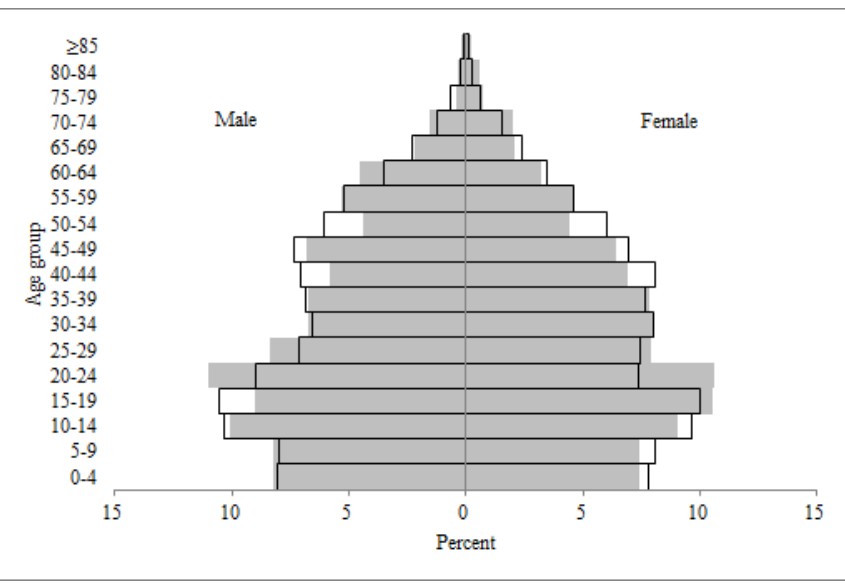

Figure 2 Age and sex distribution of the population. The shaded bars indicate the age and sex distribution for Birbhum District, West Bengal, India, National Family Health Survey, 2015-2016, and the clear outlined bars show the corresponding data for the Birbhum Population Project, 2017.

external validity of this study findings. As this study setting is limited to a rural region of Birbhum district of the state of West Bengal, a precaution on generalising the findings of this study to the other rural areas of India is needed. Fifth, a very low (24 of $2320 \mathrm{VA}$ ) level of discordance between physicians may not match with existing literature on India. For example, causes of under-five deaths had over $30 \%$ discordance ${ }^{31}$ and auditing deaths from injury had over $20 \%$ discordance. ${ }^{32}$ But low discordance in BIRPOP-SHDS, may be due to accessibility of all information available to audit VA. Since surveyors were recruited from the BIRPOP-SHDS area, this helped build strong relations with the community which helped a great deal to gather all relevant documents and information necessary for VA, which sometime required multiple visits or phone calls to the respondents. Finally, a very low proportion of deaths in the category of 'not elsewhere classifiable (R00-R99)' was recorded-84 of total 2320 deaths $(3.6 \%)$. This could raise a doubt of misclassification as studies conducted elsewhere, such as studies in Andhra Pradesh $^{8}$ and Gadchiroli ${ }^{15}$ classified over $18 \%$ and $26 \%$ of deaths in this category, respectively. One cannot rule out misclassification, however, given the adoption of strict guideline of VA audit coupled with availability of all supporting documents required for VA audit, reduced the probability of misclassification. Despite these limitations, determination of causes of death using data for 6 consecutive years from a prospective cohort in rural India is a significant strength of this study.

Findings of this study indicate a need for devising a state action plan of mortality reduction, coupled with testing various interventions to reduce risk factors for NCDs among adults. Although reducing the burden of NCDs should be the priority, investigating the rising burden of external causes of mortality among adults and interventions to reduce death from perinatal conditions are also an immediate need. India is a signatory of various global commitments to prevent NCDs. For example, the
Sustainable Development Goal target 3.4 recommends that India make every effort to reduce by one-third premature mortality from NCDs through prevention and treatment, and promote mental health and well-being, by 2030. In line with this commitment, the 2017 National Health Policy or the National Programme for prevention and control of Cancer, Diabetes, Cardiovascular disease and Stroke were devised. ${ }^{33}$ However, further efforts are needed by the Ministry of Health and Family Welfare with the help of NITI Aayog to improve prevention of NCDs and will require the involvement of multiple stakeholders including an adaptive network governance structure where the centre coordinates with the state to ensure implementation is needed. ${ }^{34}$ This study calls for the need for more community-based or locally embedded surveillance systems to track the changing patterns in public health needs and trends, as state-level measures are not necessarily indicative of a specific rural setting.

\section{Author affiliations}

${ }^{1}$ Society for Health and Demographic Surveillance, Suri, West Bengal, India ${ }^{2}$ Department of Global Health and Population, Harvard T H Chan School of Public Health, Boston, Massachusetts, United States

${ }^{3}$ Department of Economics, University of Göttingen, Göttingen, Germany

${ }^{4}$ Centre for Modern Indian Studies, University of Göttingen, Göttingen, Germany

${ }^{5}$ Chest Clinic, DTC District Hospital and Niramoy TB Sanatorium, Birbhum, West

Bengal, India

${ }^{6}$ Rural NCDs and Tribal Health Programme, Society for Education Action and Research in Community Health, Gadchiroli, Maharashtra, India

${ }^{7}$ Indian Council of Medical Research-National Centre for Disease Informatics and Research, Bengaluru, Karnataka, India

${ }^{8}$ Department of Hepatology, School of Digestive and Liver Diseases, Institute of Post Graduate Medical Education and Research, Kolkata, West Bengal, India ${ }^{9}$ Indian Institute of Liver and Digestive Sciences, Kolkata, West Bengal, India ${ }^{10}$ Department of Epidemiology, Harvard T H Chan School of Public Health, Boston, Massachusetts, United States

${ }^{11}$ Department of Nutrition, Harvard T H Chan School of Public Health, Boston, Massachusetts, United States

Acknowledgements Authors are indebted to the entire Birbhum Population Project team for recording, compiling and maintaining the verbal autopsy database. The authors are thankful to households that participated in the verbal autopsy survey. We gratefully acknowledge the feedback from Professor Zulfiqar Ahmed Bhutta, Robert Harding Chair in Global Child Health and Policy at The Hospital for Sick Children (SickKids), Toronto, Ontario, Canada, and Professor Anand Krishnan of the Centre for Community Medicine, All India Institute of Medical Sciences, New Delhi, at different stages of preparing the manuscript. Authors are grateful to the Bernard Lown Scholars in Cardiovascular Health Program of the Department of Global Health and Population, Harvard T H Chan School of Public Health, for its assistance with an open access publication fee.

Contributors RKR and $A B$ conceived and designed the study. RKR and $A B$ performed the analysis, and RKR prepared the first draft. $A B, S M$ and KC participated in auditing verbal autopsy. YK, PM, AC and WF critically reviewed results and advised in revising analysis. All authors contributed in revising and finalising the report. All authors approved the content presented in the study.

Funding This work was supported by the West Bengal State Department of Health and Family Welfare, India (Memo number: HF/O/MERT/1464/HSL (MISC) — 35/2008).

Disclaimer The funders had no role in the design/conduct of the study, collection/ analysis/interpretation of the data, and preparation/review/approval of the manuscript.

Map disclaimer The depiction of boundaries on this map does not imply the expression of any opinion whatsoever on the part of BMJ (or any member of its group) concerning the legal status of any country, territory, jurisdiction or area or of its authorities. This map is provided without any warranty of any kind, either express or implied. 
Competing interests None declared.

Patient consent for publication Not required.

Ethics approval Ethical approval was obtained from the institutional ethics review board of the Birbhum Population Project (BIRPOP), appointed by the chairperson of the Society for Health and Demographic Surveillance (SHDS). While collecting the data on causes of death, informed written consent was obtained from the respondent with a declaration from BIRPOP-SHDS that individual identifiers will be removed if dataset is made public. The reference number of this study approval is SHDS/13/2010-11.

Provenance and peer review Not commissioned; externally peer reviewed.

Data availability statement Data are available upon reasonable request.

Open access This is an open access article distributed in accordance with the Creative Commons Attribution Non Commercial (CC BY-NC 4.0) license, which permits others to distribute, remix, adapt, build upon this work non-commercially, and license their derivative works on different terms, provided the original work is properly cited, appropriate credit is given, any changes made indicated, and the use is non-commercial. See: http://creativecommons.org/licenses/by-nc/4.0/.

\section{ORCID iDs}

Rajesh Kumar Rai http://orcid.org/0000-0002-5249-9937

Yogeshwar V Kalkonde http://orcid.org/0000-0003-3543-3618

Wafaie W Fawzi http://orcid.org/0000-0002-2908-600X

\section{REFERENCES}

1 India State-Level Disease Burden Initiative Collaborators. Nations within a nation: variations in epidemiological transition across the states of India, 1990-2016 in the global burden of disease study. Lancet 2017:390:2437-60.

2 Setel PW, Macfarlane SB, Szreter S, et al. A scandal of invisibility: making everyone count by counting everyone. Lancet 2007;370:1569-77.

3 Mikkelsen L, Phillips DE, AbouZahr C, et al. A global assessment of civil registration and vital statistics systems: monitoring data quality and progress. Lancet 2015;386:1395-406.

4 Kalkonde YV, Deshmukh MD, Sahane V, et al. Stroke is the leading cause of death in rural Gadchiroli, India: a prospective communitybased study. Stroke 2015;46:1764-8.

5 Mukherjee S, Chaudhuri A, Barik A. New health policy and chronic disease: analysis of data and evidence. Econ Political Wkly 2015;50:21-4.

6 Ghosh S, Barik A, Majumder S, et al. Health \& Demographic Surveillance System Profile: The Birbhum population project (Birbhum HDSS). Int J Epidemiol 2015;44:98-107.

7 Nongkynrih B, Anand K, Kapoor SK. Use of verbal autopsy by health workers in under-five children. Indian Pediatr 2003;40:766-71.

8 Joshi R, Cardona M, lyengar S, et al. Chronic diseases now a leading cause of death in rural India--mortality data from the Andhra Pradesh Rural Health Initiative. Int J Epidemiol 2006;35:1522-9.

9 Registrar General of India, Sample Registration System Collaborators, Centre for Global Health Research. Verbal autopsy (VA) operations manual St Michael's Hospital, University of Toronto; 2013.

10 World Health Organization. International statistical classification of diseases and related health problems, 10th revision. Geneva; 2011.

11 StataCorp. Stata statistical software: release 14. College Station, TX: StataCorp LP, 2015.

12 Office of the Registrar General \& Census Commissioner. SRS bulletin, sample registration system (volume 51, number 1) Ministry of Home Affairs, Government of India; 2017.
13 Ministry of Health and Family Welfare. National health policy 2017. government of India; 2017.

14 Streatfield PK, Khan WA, Bhuiya A, et al. Cause-Specific mortality in Africa and Asia: evidence from indepth health and demographic surveillance system sites. Glob Health Action 2014;7:25362.

15 Kalkonde Y, Deshmukh M, Kakarmath S, et al. A prospective study of causes of death in rural Gadchiroli, an underdeveloped district of India (2011-2013). JoGHR 2019;3:e2019009.

16 Office of the Registrar General \& Census Commissioner. Causes of death Statistics- 2007-2013 Ministry of Home Affairs, Government of India; 2014.

17 Ke C, Gupta R, Xavier D, et al. Divergent trends in ischaemic heart disease and stroke mortality in India from 2000 to 2015: a nationally representative mortality study. Lancet Glob Health 2018;6:e914-23.

18 Rai RK, Jaacks LM, Bromage S, et al. Prospective cohort study of overweight and obesity among rural Indian adults: sociodemographic predictors of prevalence, incidence and remission. BMJ Open 2018;8:e021363.

19 Barik A, Das K, Chowdhury A, et al. Metabolic syndrome among rural Indian adults. Clin Nutr ESPEN 2018;23:129-35.

20 Barik A, Mazumdar S, Chowdhury A, et al. Physiological and behavioral risk factors of type 2 diabetes mellitus in rural India. BMJ Open Diabetes Res Care 2016;4:e000255.

21 Rai RK, Kumar C, Singh PK, et al. Incidence of prehypertension and hypertension in rural India, 2012-2018: a sex-stratified populationbased prospective cohort study. Am J Hypertens 2020;33:552-62.

22 Barik A, Shah RV, Spahillari A, et al. Hepatic steatosis is associated with cardiometabolic risk in a rural Indian population: a prospective cohort study. Int J Cardiol 2016;225:161-6.

23 Das SK, Banerjee TK, Biswas A, et al. A prospective communitybased study of stroke in Kolkata, India. Stroke 2007;38:906-10.

24 lqbal A, Shirin T, Ahmed T, et al. Childhood mortality due to drowning in rural Matlab of Bangladesh: magnitude of the problem and proposed solutions. J Health Popul Nutr 2007;25:370-6.

25 Salve H, Kumar R, Sinha S, et al. Suicide an emerging public health problem: evidence from rural Haryana, India. Indian J Public Health 2013;57:40-2.

26 Barik A, Sarkhel S, Basu S, et al. Probable psychiatric disorder in a rural community of West Bengal, India. Soc Psychiatry Psychiatr Epidemiol 2017;52:1495-500.

27 Barik A, Rai RK, Gorain A, et al. Socio-Economic disparities in tobacco consumption in rural India: evidence from a health and demographic surveillance system. Perspect Public Health 2016;136:278-87.

28 Leitao J, Desai N, Aleksandrowicz L, et al. Comparison of physician-certified verbal autopsy with computer-coded verbal autopsy for cause of death assignment in hospitalized patients in low- and middle-income countries: systematic review. BMC Med 2014:12:22.

29 Piffaretti C, Moreno-Betancur M, Lamarche-Vadel A, et al. Quantifying cause-related mortality by weighting multiple causes of death. Bull World Health Organ 2016;94:870-9.

30 International Institute for Population Sciences (IIPS) and ICF. National family health survey (NFHS-4), 2015-16: India. Mumbai: IIPS 2017.

31 Morris SK, Bassani DG, Kumar R, et al. Factors associated with physician agreement on verbal autopsy of over 27000 childhood deaths in India. PLoS One 2010;5:e9583.

32 Hsiao M, Morris SK, Bassani DG, et al. Factors associated with physician agreement on verbal autopsy of over 11,500 injury deaths in India. PLoS One 2012;7:e30336.

33 Ministry of Health and Family Welfare, Government of India. National programme for prevention and control of cancer, diabetes, cardiovascular disease and stroke Director General of Health Services; Ministry of Health \& Family Welfare. Government of India; 2013.

34 Mondal S, Van Belle S. India's NCD strategy in the SDG era: are there early signs of a paradigm shift? Global Health 2018;14:39. 